\title{
The Bizarre Inception Of Memories - An Outright Perlustration
}

\section{Ancy Antony}

Postgraduate Student

Asst. Professor Shilpa Nair S

Department of English

Amrita School of Arts and Sciences

Amrita Vishwa Vidyapeetham

Amritapuri - 690525, Kerala, India

\section{Anjali J}

Postgraduate Student

Asst. Professor Shilpa Nair S

Department of English

Amrita School of Arts and Sciences

Amrita Vishwa Vidyapeetham

Amritapuri - 690525, Kerala, India

\section{Jesline Samuel}

Postgraduate Student

Asst. Professor Shilpa Nair S

Department of English

Amrita School of Arts and Sciences

Amrita Vishwa Vidyapeetham

Amritapuri - 690525, Kerala, India

Article History: Received: 10 November 2020; Revised 12 January 2021 Accepted: 27 January 2021; Published online: 5 April 2021

\begin{abstract}
The inception of things around us are neither real nor unreal, rather it is the perception and the willingness of the mind to form what is the real and the unreal. Looking into the tremendous growth and headway that has transpired in the world there is much more importance given to reality and dream. One tries to reconnoiter the already touched and the untouched range of the profundity. Science and Technology has certainly not spared anything, therefore there is a coherent study going on which deals with human memories and its effects. Memories ever elate and bring levity to the majority but the idea of memory getting influenced by the circumstances and the outside phenomenal facets are bogus. A total foreign memory can be implanted or the existing memories can be filtered using various technologies. The crux of the movie "Inception" deals with this idea of implanting false memories in other people. The characters enter the sub-consciousness of the other people through their dreams and design a surreal environment where the action takes place. Throwing light into the new millennium, the movie "Inception" has it's the utmost upshot. The film caters a different way of looking into life as so
\end{abstract}


abysmal and intense. Untold memories impinge upon the past and alters the present. The emphasis of the paper lies on the concept that every dream belong to a person and the idea of manipulating the content of someone else's memory.

KEYWORDS: Dreams, Inception, Manipulation, Memory, Reality, surreal.

Cinema for many people is an enduring tale. They started deemed everyone with diverse perspectives and provides personal refinements. Living the life tangled with insanity people always wanted to know more about the ceaseless dehiscent windows that opens throughout their journey. Hollywood cinemas predominantly construed very different way of extramundane advent of modernity. Movies excavate people into their rooted inner self where they could connect with the dream that they yearn for and provide the public with shared experience of dreams. They also have a magical ability to bring the fascinations of people into life. In an age suppressed by the outer battles and human sufferings people become agonist minded that brought pessimism into existence. Life being a garboil and people being lost in themselves, they try to find solace by seeing their life through the haze of rather perfervid imagination. Even though modernity hits the people with absurdity and ambiguity, people wanted to explore the unexplored one with the help of modernity. Science and technological progress made the people to learn about the true nature of reality. It also helps to widen the knowledge about the universe and also made the people aware about the unsettled possibilities that once believed impossible. Films are dream-like in nature. Like dreams, films affect the public on a subconscious level. The movie "Inception" starts with the ending of the story which shows that the ending of a film can also be the beginning. When the movie begins the audience are introduced to Cobb who is washed up on a beach. From the beginning itself we can understand that the movie is portrayed in a nonlinear manner, where there is a story behind how Cobb got there. To retain and control the progression of information to his viewers, Nolan utilizes a non-linear structure. The use of unusual effects, specific editing and technologies like the dream machine, the movie takes the nonlinear narrative to a modern context.

As this film has a nonlinear sequence of events, it is essential for the audience to watch all the parts of the film very clearly with a good concentration, otherwise the movie might not make sense to the audience who skips every second and important parts and events of the movie. Every moment of the movie has important events in it. Nolan wants the audience to be smart and talented enough to understand his complex movie. The complex theme is portrayed by Nolan in a manner which the viewers can understand and admire. Inception is the film that is going to survive wonderfully even after a hundred years.

Everything appears to be the inception of something from the past or broken memories. It is from the brain arises various emotions, perceptions, wisdom. Brain hold the key to layer out an individual from various experiences or inputs one had been through. The evolution of knowledge has been so regularly swelling that we are able to crack the unconsciousness of other people. The potential of human mind is infinite that we are able to code every possible chronicles from concrete to abstract. The movie "Inception" is one such film that reveals the 
potential of human knowledge to enter the sub-consciousness of the other people through their dreams and create a surrealistic environment where the action takes place. Memory is considered as the record-keeper of a soul and that is filtered and implanted in this movie.

Aristotle in his treatise "On the Soul" compares human mind as an abyss and he further explains that humans are born free of any knowledge and are merely the sum of their experiences. It is these experience that builds up an individual to such a phase where they act accordingly. Whether in case of taking decision or planning or controlling or scrutinizing, an individual needs to have knowledge and experience. These experiences and knowledge fill our consciousness and unconsciousness with elements that are reserved to be used and ignored. The way a person functions in his society is very much depended on his ego (consciousness), super-ego (conscience) and id (unconsciousness). Ideas or images are formed when one experiences a direct sense impression from the world. And thus, these direct impressions help our mind to accumulate and then gives rise to the process of thinking. The advancement of the world is at its peak and so is the aptitude of the people. According to the Association for Psychological Science, experimental research has shown that ideas can be implanted into people's minds and thus integrated into a person's memory. One can go deep down into the subconscious of another person's mind and manipulate his or her memory. The experience of the individual is altered by an external influence purposely through science or technology. It is the experience of the mind that crafts the real and the unreal.

The nature of the dreams is so unrealistic. It is believed that dream is the channel that connects our conscious mind with the unconscious. Through dreams one expresses the unexpressed or it is through dreams that one releases the repressed mind. Traumatic events like accidents, death of someone who is much attached to you, or witnessing any death all could lead different impressions in different people. The way one perceives such direct impressions would end up, at least for some, in occupying a space in the unconscious, i.e. one tries to repress those incidents which affect their psyche in the unconscious mind. Dreams either bring back these memories or try to connect them with the conscious. The movie "Inception" is centred on the model of manipulation of memory through the dream in a surrealistic milieu. The characters experience a direct sense of impression from that surrealistic space of the dream, and hence the targeted person becomes unable to realize his bizarre experience. Cobb and Arthur, the "extractors" perform inception on Robert, by using experimental military technology. Each character of the movie associated with memory extraction travel through various levels of inception through a shared dream world.

The flashbacks in "Inception" gives the movie a broader aspect. The broad theme of the film is the binary oppositions of dream versus reality or the equilibrium between what if true and what is false. An example of binary oppositions can be seen through Cobb's wife Mal, at a point she couldn't identify herself whether she's in the real world or the dream world which caused her death.

Certain scenes in the movie have so much similarities of that of a dream. In dreams, an individual cannot recall the beginning, but only the middle, likewise certain actions in the movie starts in the middle that lack proper preamble. The scene where Ariadne and Cobb having coffee is introduced in the middle of the action and thereby doesn't give the audience 
the indication that the scene is a dream and the characters are dreaming. The scene is exhibited as a usual scene but later along with Ariadne, audience realize that the characters are dreaming. Christopher Nolan brings the notion that people continuously enjoy the films and are highly gratified in it even though various sequences appear to be chaotic as people see in their dream. They seem to be real even though it starts in the middle. Like dreams, movies capture our attention and takes the people to a land of imagination and make them feel like reality even though the images are sporadic and erratic. Both affects the subconscious elements of an individual. In the movie, the scene where Cobb being chased through the streets, he gets stuck in an alley where he undergoes a difficulty that may either indicate claustrophobia that is experienced during a dream or maybe it is a technique used by the director to enhance the tension of that particular scene. Films use various dramatic effects to enhance beauty even though the scenes create a preposterous impact. The element of unreasonable images put together to create a situation can be seen in the dream too. Dreams come as a result of the images captured in the subconscious and same is in the case of films where imaginations are recreated by the subconscious mind. In dreams, sudden changes will happen and various characters will be introduced in haste during the action. As in the case of dreams, people who are not connected in the situations will appear. The entry of Saito all of a sudden in the chasing scene can be an example. People have to connect various sequence of actions to get the whole idea in a film like they do in the dreams.

Christopher Nolan attempts to bring several aspects to the movie. The movie is not barely about infiltrating an idea or the extraction of an idea but it carries deep levels of meaning. The way the director presents the movie pave way to several interpretations. He put forward the idea that the life seems to be challenging and problematic and in order to overcome it people have to accept the challenge as it is. The Limbo in the movie can also refer to the safe heaven were every one hankers to hold due to fragmented modern world. Cobb decides to do inception because of his strong desire to reunite with his children. His memories haunt his present life and that is clearly evident with the recurring occurrence of his wife Mal, in his dream heist. Cobb like a modern man questions his reality and together with his wife created a world of their own. Mal with her memories much hit on the imaginary world, started believing it to be her reality. Mal got stuck in her own world but Cobb kills his that part of subconscious to come back to reality and to move on with his children. For Cobb the leap of faith was his intense desire to reunite with his children. Limbo can be seen as a place or a state of mind where all the darkest thoughts resides. It represents the true self. These darkest thoughts locked deep inside have the ability to consume the whole person. Cobb continually haunted by the projection of his wife and the vision of his two children are his deepest thoughts. In the case of Mal, she represents the feeling of despair that affects a person. She believes that she can no longer connect with the people around her so she decides that the only way to return to real world is to kill herself and to wake up in her reality. Characters uses dreams to escape the reality which points out the common trait of escapism in humans. Mal's obsession to the dreamy world serves as reminder for all others that those who are enthralled or too much reliant to a dreamy land will end up in destruction. Here Nolan very richly shows the drawback of dream and its effects. In the movie the talent of crafting memories is misused and mistaken by the crafter itself. They become so indulged in it, for example in case of Mal she ends up 
committing suicide in order to get back into her limbo. Cobb on the other hand uses his talent to tap business conglomerate and ship money and other dealings. The ending of the movie is packed with debate and confusion. Nolan said that he purposely skipped and left it incomplete, in order for one to chase after their dream and how reality is being chased by many in their own way.

The film denotes not only the scientific and technological advances but also the social, political and economic facet of society. The movie holds references to classical relic by the character Ariadne. She is the one who is entrusted to create a labyrinth dreamscape to deceive their victims. Ariadne is named after the mythological character who helps Theseus through the labyrinth in the myth of Theseus and the Minotaur. In the myth, Theseus confront the strange tradition of sacrificing boys and girls to Minotaur. As well in the movie, Cobb is the first to experiment the concept of inception. Like Theseus, Cobb was resolute and was ready to take up the risk. Cobb defeats the external forces trying to imprison him and manages to succeed. Like Theseus leaving his family and later Ariadne draws another similarity to Cobb leaving his children. Director uses myth as a unifying link between past and present.

Director displays his brilliance through the names of the characters. Each character is given their names according to their role in the movie. The name 'Mal' in French means 'bad'. The name indicates a negative shade which comes true in the plot. The name 'Eames' in the movie is a common surname to architects.' Dominic Cobb', in Latin Dominic means 'belonging to God'. He represents a God like figure by doing inception which is far beyond human believes. The name 'Arthur' can be related to the King Arthur who believed to be never dead instead put to sleep and is likely to wake up at any moment. The name 'Yusuf' also have significance. In Quran, the story of Yusuf begins with a dream, similarly in the movie it is Yusuf who instigate the dream heist. Director tries to create a new world with complex characters. Analyzing the names of the characters it's evident that the director not only focuses upon the advances of science but all other spheres of life.

Everyone yearns to retain in a dreamy borough and hope to bolster it within their hands to get away from this brisk world. The world with its wax and wane has forced our mind to relax and find solace in the lap of the surrealistic environment where our dreams materialize. Inception helps to escape from reality to fantasy.

There have been studies going on in this field, to implant people's memory and make them feel the unexperienced. The paper "Nature Neuroscience" describes that artificial memories can be crafted in the lack of any real experience. The implanted memory test is carried out in animals and the results proved that artificial memory was indistinguishable from natural memory. The research doesn't aim to create characters like Cobb and Arthur to encourage dream heist, and not like Mal who take advantage of her talent and believe in the unrealistic limbo thus bringing doom to her life and others around her. The idea of inception can really be used in such a way to bring up those struggling with mental conditions like depressions, autism and traumas. Also, this process of inception can become magical in mending memories lost to time and setting mind with the desirable memories. The accuracy of the theory is not yet proved but with time anything can be made possible. Recent studies are swelling up with ideas that one can incept without the awareness of the target person. Thus, no existence is possible in this universe without the essence of memories, and so is our dreams. 


\section{WORK CITED:}

[1]. About Sarahana Interactive designer and co-founder of The Short Form.full profile/ twitter/ www. (2014, September 11). Inception: The meaning behind character names. https://imposemagazine.com/music/inception-meaning-behind-character-names

[2]. Inception movie Analysis - mythology (ARIADNE, Theseus, Sirens). (2011, September 19). https://thehumanfiction.wordpress.com/2011/09/18/inception-movie-analysis-\%E2\%80\%93mythology-ariadne-theseus-sirens/

[3]. The psychological science of "inception". (2010, August 12). https://www.psychologicalscience.org/news/releases/the-psychological-science-of-inception2.html

[4]. What part of the brain is the soul/mind located? - education - nigeria. (n.d.). https://www.nairaland.com/5427998/what-part-brain-soul-mind

[5]. Young, C. (2019, September 02). Inception: Scientists have successfully implanted an artificial memory. https://interestingengineering.com/inceptionscientists-have-successfully-implanted-an-artificialmemory\#: :text=Artificial\%20thoughts, \%20indistinguishable\%20from\%20a\%20natural\%20 memory 